INGENIERÍA QUÍMICA

\title{
Cálculo de parámetros cinéticos en reacciones foto-catalíticas usando un modelo efectivo de campo de radiación
}

\author{
Fiderman Machuca-Martínez ${ }^{1 \S}$ \\ ${ }^{18}$ Escuela de Ingeniería Química, Universidad del Valle, Cali, Colombia. \\ fiderman.machuca@correounivalle.edu.co
}

\section{Resumen}

(Recibido:Julio 28 de 2010 - Aceptado: Marzo 4 de 2011)

\begin{abstract}
En este estudio se evaluó el efecto de la geometría y la concentración de substrato en la determinación de rendimientos cuánticos globales del proceso. Los rendimientos cuánticos se obtuvieron bajo un enfoque de parámetros globales constantes, fundamentados en las propiedades isotrópicas del campo radiante y de distribución perfecta de partículas en la fase fluida. Se usó un modelo idealizado para la cuantificación del campo de radiación y las expresiones matemáticas para la velocidad de reacción y la energía global efectiva absorbida del proceso (OVRPA) por medio de una solución aproximada de la ecuación de transferencia radiativa (RTE). Los resultados obtenidos para los rendimientos cuánticos permitieron mostrar la naturaleza no intrínseca de los parámetros cinéticos por la fuerte influencia de la geometría asociada a la dependencia con la energía radiante global absorbida por el sistema, evaluando estos parámetros foto-cinéticos a concentración inicial de ácido dicloroacético (DCA) constante. El error relativo global es menor al $2.5 \%$ y los coeficientes de correlación son mayores a 0.97 entre los datos de simulación y los datos experimentales utilizados.
\end{abstract}

Palabras Claves: Acido dicloroacético, Rendimientos cuánticos no intrínsecos, Campo de radiación efectiva, Velocidad volumétrica global de absorción de fotones.

CHEMICAL ENGINEERING

\section{Calculation of kinetics parameter on photo-catalytic reactions using an effective radiation field model}

\begin{abstract}
This study assessed the effect of the geometry and concentration of substrate in the determination of overall quantum yields. The quantum yields were obtained under an approach of constant global parameters based on the properties of isotropic radiant field and perfect distribution of particles in the fluid phase. An idealized model for quantifying the radiation field was used for reaction rate and overall volumetric rate of photon absorption (OVRPA) were obtained by means of an approximate solution of the radiative transfer equation (RTE). The results for quantum yields allowed to show the non-intrinsic nature of the kinetics parameters because of the strong influence of geometry associated to the dependence on the radiant energy absorbed by the system, evaluating these photo-kinetic parameters at constant initial concentration of dichloroacetic acid (DCA). The overall relative error between the simulation and experimental data is less than $2.5 \%$ and the correlation coefficients are greater than 0.97 .
\end{abstract}

Keywords: Dichloroacetic acid, Non-intrinsec quantum yields, Effective radiation yield, Overall volumetric absorption photon rate. 


\section{Introduction}

The heterogeneous photocatalytic processes are strongly influenced by four key components: system reactive (substrate), catalyst (semiconductor), geometry reactor (reactor type) and radiation field (luminous flux). The geometry and radiation field introduce a no-intrinsic nature to this type processes (reflected in kinetic of reaction rate), these characteristics are the major differences with the conventional chemical processes (Alfano \& Cassano, 2009; Braham \& Harris, 2009; Liu \& Zhao, 2010; Herrmann, 2010).

The performance of photocatalityc process depends critically on the amount of incident radiation that can be used to activate the catalyst particles and therefore it requires a correct quantification of the volumetric rate of energy absorption (VREA). This in turn will allow an adequate description of the kinetic parameters such as quantum yields (Sagawe et al., 2010; Machuca et al., 2008; Kuhn et al., 2004).

This parameter has been used in various studies of photocatalytic reaction. For the evaluation of different materials, in monitoring the photocatalytic reactions of pure compounds and mixtures, follow up the production of $\mathrm{OH}$ radicals, in modeling and evaluation of photoreactors, scaling of processes and reactors (Egerton and Mattinson, 2010; Liu and Zhao, 2010; Li Puma et al., 2010; Serrano et al., 2009; Siamak \& Fariborz, 2010; Zhang and Anderson, 2010).

Several substances have been proposed for the calculation of quantum efficiency, there are found from pure substances to complex mixtures; e.g., pesticides, endocrine disrupting chemicals and microorganisms. Among the more pure substances used are phenol and its derivatives, ethanol, inorganic and organic subtances and the dichloroacetic acid (Ballari et al., 2010; Egerton and Mattinson, 2010; Sagawe et al., 2010; Trujillo et al., 2010).

In particular, the DCA has been implemented as a key component of heterogeneous actinometry and/or model substance for kinetic studies of heterogeneous photocatalytic systems, due to the simplicity of the stoichiometric equation and simple experimental tracking, as well as its physical and chemical properties that allow it to be considered a valid chemical actinometer for heterogeneous photodegradation reactions (Zalazar et al., 2005; Machuca et al., (2008); Ballari et al., 2010).

The importance of assessing the quantum yields as comparison parameters is established by the nature of the induction processes of electron hole $(\mathrm{e}-) /(\mathrm{h}+)$ pairs at the semiconductor/solution interface, where the reaction rate in the primary stage of the catalyst excitation is considered as the quantum yield of the process, Rothenberger (1985), Serpone (1997).

Nevertheless, the conventional definition of quantum yield used in heterogeneous photocatalysis (which relates the number of moles processed per unit of absorbed energy by the photochemical semiconductor), Serpone (1997), is strongly associated to reference states that are obtained by homogeneous actinometry leading to apparent quantum yield parameters in order to extrapolate results from simple systems to complex reaction mixtures, while retaining the same geometry reaction, Zalazar et al. (2005), Brandi et al. (2003), Trujillo et al. (2010).

The quantum yields obtained by this route are usually calculated by adjusting experimental data from simple actinometric reactions, coupled to a solution of the radiative transfer equation, Duderstadt (1979), resulting in values that are not necessarily unique to the reaction system, i.e. nonintrinsic quantum yields, due to the heavy dependence of the radiant field for constant flow of photons, in relation to the geometry of the system. So, the evaluation of the global quantum yield and the overall volumetric rate of photonic adsorption can be made by fitting results of heterogeneous actinometrical experiments or using an appropriate phase field model coupled with the RTE. (Machuca et al., 2008, Mueses et al. 2008).

Among the least studied variables in heterogeneous photocatalytic reaction in determining the quantum yield is the type of reactor and the effect of substrate concentration. 
This keys components, into all heterogeneous photocatalytic processes, have been evaluated in previous investigations, Blanco et al. (2001), Brandi (2003), Dijkstra et al. (2003), Bandala et al. (2004), Mueses (2008), where overall photodegradation convertion have been assessed in irradiated reactors with direct and diffuse solar or artificial polychromatic radiation at low concentrations of substrate in different reaction systems but no related with the quantum and photonic parameters.

However, few studies have been reported with comparative theorical and experimental evidence that differentiate the significance of these two effects (concentration and geometry) and that assess the parameters of photo-kinetic reactions, as quantum yields and rate of photon absorption, by means of the evaluation of a single reaction system in different geometrical configurations, Bandala et al. (2004), Brucato et al. (2007), Alfano \& Cassano (2009).

This paper aims to show the effect of geometric configuration and the initial concentration of substrate for three reaction systems (compound parabolic collector - CPC, tubular, and axial) on quantum yields using a new model of radiation field and the data from actiometrical heterogenous reaction.

\section{Mathematical model}

Machuca et al. (2008) have proposed a model for calculating photo-kinetic parameter based on a methodology of isotropic global parameters, quantum yield $\left(\Phi_{g}\right)$ and overall volumetric rate of photon absorption OVRPA $\left(E_{g}^{a}\right)$. This model was validated from the DCA photocatalytic degradation data in a differential perfect-mixture reactor. The effective radiation field model (ERFM) used in this study is based on the modification of the RTE equation assuming an isotropic field, the conceptual basis of the model without the mathematical rigor was published partially by Mueses and Machuca (2010b).

The formulation of the constituent equations of the system supports the following general considerations without breaking the basic principles of photocatalysis, Herrmann (2010):
Isothermal and isobaric system, heterogeneous system with isotropic distribution of perfect mix, fluid + particles, effective radiation field with constant energy, monocromatic radiation, constant optics and isotropic absorption properties, No radiation absorption in the fluid phase, heterogeneous photocatalytic reaction controlled by the primary stage of the semicondutor excitation and light scattering effects with function of isotropic phase.

The global structure of systems include the reaction rate model for DCA, mass balance for the reactors, radiative energy balance from the absorption model, effective radiation model from emission model, and the OVRPA. In forthcoming publications an extension and validation of mathematical develepment will be made.

\subsection{Reaction rate model}

For this study, it uses the DCA photocatalytic degradation as model reaction. Zalazar et al. (2005) proposed a mechanism and an expression of reaction rate for the DCA photodegradation based on the direct attack by the holes $\left(h^{+}\right)$ generated during the activation of the catalyst, towards the dichloroacetate ion $\left(\mathrm{CHCl}_{2} \mathrm{COO}^{-}\right)$. In a previous work, Machuca et al. (2008), the expression of reaction rate was modified in terms of overall quantum yield $\left(\Phi_{g}\right)$ and the overall volumetric rate of photon absorption $\left(E_{g}^{a}\right)$. The resulting expression is shown in equation $(1)$ :

$$
\begin{gathered}
R_{D C A}=\frac{2 \Phi_{g} E_{g}^{a}}{1+\left[1+\frac{\beta}{C_{D C A}}\right]^{\frac{1}{2}}} \\
\beta\left(K_{O b s}, \Phi_{g}\right)=\beta=2 \frac{K_{O b s}}{C_{C a t}^{2} C_{O 2}} \Phi_{g} E_{g}^{a}
\end{gathered}
$$


Where $\left(K_{\text {obs }},{ }_{g}\right)$ is a function of photocatalytic kinetic parameters, $K_{O b s}$ is an adjustment kinetic parameter, $C_{D C A}$ is the concentration of DCA, $C_{O 2}$ is the oxygen concentration, and $C_{C a t}$ the catalysts concentration.

\subsection{Mass balance: the generating equation}

The material balance is independent of the geometry of the evaluated reactors. The resulting expression for batch systems is an integerdifferential function as shown in equation (3):

$$
\left.\frac{d C_{D C A}}{d t}\right|_{T k}=-2\left(\frac{1}{v_{T}}\right) \int_{0}^{v_{R}} \frac{\Phi_{g} E_{b}^{a}}{1+\left[1+\frac{\beta}{C_{D C A}}\right]^{\frac{1}{2}}} d v
$$

Where $T_{K}$ refers to the volume of the absorber, $v_{T}$ is the system total volume, and $v_{R}$ is the reaction volume.

The isotropic nature of the kinetic parameters, the concentration of reagents and catalyst particle distribution, implies that equation (3) does not depend on the volume of the reactor, and becomes a non-linear ordinary differential equation depending on the concentrations of reactive species and time. The functional form of the solution is given by (4):

$$
\begin{aligned}
& C_{D C A}+\sqrt{C_{D C A}\left(C_{D C A}+\beta\right)}+ \\
& \frac{\beta}{2} \operatorname{Ln}\left\{\left(C_{D C A}+\beta\right)+\sqrt{C_{D C A}\left(C_{D C A}+\beta\right)}\right\} \\
& -f\left(C_{D C A, 0}\right)=-2\left(\frac{v_{R}}{v_{T}}\right) \Phi_{g} E_{g}^{a} t
\end{aligned}
$$

Where $f\left(C_{D C A, 0}\right)$ is the solution evaluated at the initial condition $(t=0)$. Equation (4) is the generating equation, which links the concentration of DCA depending exclusively on time and has only two adjustable parameters from experimental data: the overall quantum yield and the $K_{\text {obs }}$ constant.

\subsection{Radiative energy balance}

The radiation field properties can be defined under the foundations of Cassano et al. (1995) and through the use of the one-dimensional equation of radiative transfer, modified to an isotropic effective radiation field with constant energy $I_{N}$. Mathematical procedure in detail was developed by Mueses (2008), Mueses and Machuca (2010b).

The independent RTE equation of the geometry of the reactor is:

$$
\begin{aligned}
& \frac{d I_{N}}{d s}+\left[\left(\kappa_{v}+\sigma_{v}\right) I_{N}\right]- \\
& \frac{\sigma_{v}}{4 \pi} I_{N} \int_{\vec{\Omega}=4 \pi} \rho\left(\vec{\Omega} \rightarrow \overrightarrow{\Omega^{\prime}}\right) d \Omega^{\prime}
\end{aligned}
$$

Where $I_{N}$ is the net incident radiation energy on the semiconductor particles, $\kappa_{v}, \sigma_{v}$ are the volumetric absorption and scattering coefficients, Cassano et al. (1995): The integral term is a function of elastic scattering and $s$ is the geometry reference coordinate: $r$ for tubular reactor radio and $z$ for axial configuration, Alfano et al. (1995)

\subsubsection{Effective radiation field}

The energy radiation field can be calculated by applying the following assumptions: (i) it is possible to redistribute the total energy $-_{F}$ of an incident photon flux on an energy absorber in a constant energy field (energy pit), ${ }_{F, T}$ which surrounds isotropically the element of absorption, regardless of the direction and spreading frequency and (ii) the radiant field inside the reactor remains isotropic nature and is spread evently throughout the system volume. Similar concepts were used by Ballari et al. (2010) in the study of the mass transfer limitations in slurry photocatalytic reactors, and Sagawe et al. (2010) in the analysis of photoreactors by observed photonic efficiency.

In particulary, the total effective radiant energy in a cylindrical absorber with absorption surface area $S_{A}=S_{H}^{I}+S_{L}^{I}$ with $S_{H}^{I}$ and $S_{L}^{I}$ as the directly illuminated surface by a radiating source and the not illuminated surface respectively can be estimated using the following equation: 


$$
\int_{S_{H}^{I}} \zeta_{F}(\vec{x}, \vec{\Omega}) d\left(S_{H}^{I}\right)=\int_{S_{A}} I_{N} d\left(S_{A}\right)=I_{N} \int_{S_{A}} d\left(S_{A}\right)
$$

Now, considering the emission source and following the tenets for modeling lamp emission proposed by Cassano et al. (1995), the net radiation energy field entering the absorber is expressed as follows:

$$
I_{N, 0}=\zeta_{F, T}=\frac{A^{E f f}}{\pi^{2} D_{L} L_{L}\left(\lambda-\lambda_{0}\right)} \int_{\lambda} \eta_{L} P_{\lambda} \mathrm{Y}_{R} d \lambda
$$

Where $A^{E f f}$ is proposed as the quotient between the illuminated area $S_{H}^{I}$ and the total absorption area $S_{A} ; D_{L}$, $L_{L}$ and ${ }_{L}$ correspond to the diameter, length and total number of radiation lamps respectively; $\left(\lambda-\lambda_{0}\right)$ is the lamp wavelength operating range, $P_{\lambda}$ is the photochemical power of the lamps and $Y_{R}$ is the transmittance coefficient of the wall of the absorber.

Therefore, this approach can be applied without homogeneous actinometry requirements for estimating overall quantum yields, coupled with the concept of heterogeneous actinometry and models for the radiation field.

\subsubsection{OVRPA calculation and net absorbed energy}

In mathematical terms, the overall volumetric rate of photon absorption can be defined as the integration throughout the volume of reaction of the product between the semiconductor volumetric absorption coefficient and the net incident energy (by analogy with the volumetric local rate of photon absorption, LVRPA), as shown by equation (8):

$$
E_{g}^{a}=\frac{1}{v_{R}} \int_{v} \kappa_{v} I_{N}(v) d v
$$

The net effective energy absorbed by particles of catalyst can be estimated from the solution of the RTE equation (equation 5) with a function of isotropic phase with elastic scattering and considering also an adimensional function of fraction of absorbed radiation, defined by equation 9:

$$
\varphi_{N}^{E f f}=\frac{E_{g}^{a}}{E_{g, 0}^{a}}=\frac{1}{v_{R}} \int_{v} I_{N}^{E f f}(v) d v
$$

With:

$$
I_{N}^{E f f}(v)=\frac{I_{N}}{I_{N, 0}}
$$

Where $I_{N}^{E f f}$ is the net energy absorbed by the semiconductor particles in the volume of reaction, $I_{N, 0}$ is the total net isotropic energy at the entrance of the reactor and $E_{g, 0}{ }^{a}$ is the overall volumetric rate photon absorption on the wall of the reactor.

The equations of the model can be transformed by consideration of an adimensional variable $\chi$ of effective length. For tubular reactors with radial configuration is defined by equation (11) and axial by equation (12):

$$
\begin{gathered}
\chi=1-\frac{r}{\xi} \\
\chi=\frac{z}{\xi}
\end{gathered}
$$

With $\xi$ is the total radio $R$ of the absorber for radial tubular, and length $L$ for axial configurations.

The solution of the RTE equation and the implementation of equations (9) to (12) generate the following expressions for evaluating the overall absorbed fraction in all three geometric configurations:

For radial-tubular reactors:

$\varphi_{N}^{E f f}(\chi)=1+2 \sum_{m=1}^{m=2} \frac{(-1)^{m}}{\left(\kappa_{v} \xi\right)^{m}}\left[1-(1-\chi)^{\left.\frac{2}{m}-1\right)} \exp \left(-\kappa_{v} \xi \chi\right)\right]$ 
For cylindrical-axial:

$$
\varphi_{N}^{E f f}(\chi)=1+\frac{1}{\left(\kappa_{v} \xi\right)} \exp \left(-\kappa_{v} \xi \chi\right)
$$

Both expressions are governed by the general boundary condition:

$$
\chi=0 \rightarrow \varphi_{N}^{E f f}=1
$$

\subsection{Generalized scheme solution}

The generating function (equation 4) has two adjustable parameters that can be obtained through experimental photodegradation data, Mueses (2008). A generalized method of nonlinear least squares was used to obtain the values of overall quantum yield $\Phi_{g}$ and the adjustment constant $K_{o b s}$. The method uses a Broyden type modification of the generalized Newton-Raphson method coupled to a new concept of "nonnegativity of the quantum yield", this new concept restricts the method to positive values but lower than unity in the overall quantum yield, Broyden (1965), Mueses \& Machuca (2010a).

The value of the initialization parameters was determined from a modified method of initial velocity, Wold (1993), in conjunction with the reaction rate equation (equation 1). The expressions obtained are shown in equations 16 and 17:

$$
\begin{gathered}
\Phi_{g}^{(0)}=\frac{1}{E_{g}^{a}} \lim _{t \rightarrow 0}\left[\left\langle R_{D C A}\right\rangle_{R}\right] \\
K_{O b s}^{(0)}=\lim _{t \rightarrow 0}\left[\tau=\left\langle R_{D C A}\right\rangle_{R}-R\left(K_{O b s}\right)\right]
\end{gathered}
$$

Where $\left\langle R_{\mathrm{DCA}}\right\rangle_{R}$ is the average reaction rate in the reactor and $\tau$ is a function of the discrepancy between the initial average reaction rate and the evaluation of the expression of reaction rate $R\left(K_{o b s}\right)$.

\section{Results and discussion}

To study the geometry effect and initial concentration in the DCA photodegradation, experimental data reported previously were considered, Mueses et al. (2008). Tthis paper shows in detail, obtaining experimental data for three lab-scale reactors with UV radiation and using P-25 Degussa $\mathrm{TiO}_{2}$. Summarizing the previous work, a CPC reactor, a tubular and a cylindrical-axial reactor were evaluated. The CPC and tubular reactors were of equal size and radial configuration of radiation entrance (except for collectors); the axial reactor was smaller and was named that way because the incident radiation comes lengthwise through the axial axe of the container. The optical properties of the semiconductor (titanium dioxide), volumetric absorption coefficient and volumetric scattering coefficient, were taken from Cabrera et al. (1996) and the transmittance coefficient of the material of the reactor was taken from Alfano et al. (1995).

The implementation of the scheme solution allows obtaining overall quantum yields and the adjustment constant, for any substance under heterogeneous photocatalytic reaction. For the DCA, the photodegradation in all three reactors was evaluated at different initial concentration of substrate, those results are presented in Table 1.

The obtained quantum yields are positive and less than unity, consistent with the physical restraint of the conventional definition (Serpone, 1997) and the concept of non-negativity of quantum yield (Mueses \& Machuca, 2010a), without breaking the fundamental principles of catalysis (Herrmann, 2010). But its order of magnitude is low and possibly attributed to the type of radiation and its photochemical power.

The results can be explained as follows: the behavior of quantum yield may be due to the electron flow goes from the $\mathrm{DCA}$ to $\mathrm{TiO}_{2}$. Then, assuming that the reaction started after reaching adsorption equilibrium, increasing the initial concentration of DCA increases the amount of molecules adsorbed on the surface, so that more holes are stabilized by electrons from the DCA, so it oxidized and increases increasing performance 
Table 1. Quantum yields and adjustment constants for different reactors and initial concentration

\begin{tabular}{lccc}
\hline Reactors & $\begin{array}{c}{[\mathrm{DCA}]_{0}} \\
\mathrm{ppm}\end{array}$ & $\begin{array}{c}\Phi_{\mathrm{g}} \times 10^{3} \\
\left(\mathrm{~mol} \cdot \mathrm{Eins}^{-1}\right)\end{array}$ & $\begin{array}{c}K_{\text {Obs }} \times 10^{10} \\
\left(\mathrm{~mol} \cdot \mathrm{min} \cdot \mathrm{s}^{2} \mathrm{~cm}^{-9}\right)\end{array}$ \\
\hline CPC & 120 & 3.48679 & 5.4181 \\
& 60 & 3.26716 & 5.0906 \\
& 30 & 1.54054 & 9.9063 \\
Tubular & 120 & & 3.6354 \\
& 60 & 2.45819 & 4.5075 \\
& 30 & 1.97430 & 4.3931 \\
Axial & 120 & 1.34513 & 20.275 \\
& 60 & & 10.124 \\
& 30 & 0.39367 & 21.305 \\
\hline
\end{tabular}

degradation and therefore the quatum yields. Additionally, it is likely that the free electrons in the conduction band of $\mathrm{TiO}_{2}$ leading to the formation of superoxide radical $\left(\mathrm{O}_{2}-\bullet\right)$ and these could increase the oxidation of DCA.

The emission system of the reactors has high photochemical power but low-energy incident photons. The wavelength of radiation of the lamps is $365 \mathrm{~nm}$ (near the upper limit of UV). The energy of the incident photons is close to the optical absorption barrier of the semiconductor (P-25 Degussa $\mathrm{TiO}_{2}$ ), significantly below $385 \mathrm{~nm}$ (Wold, 1993; Siamak and Fariborz, 2010), but near the band gap of the semiconductor.

The forbidden band-gap energy $E_{\text {gap }}{ }^{+}$should be lower than the radiated energy on the catalyst particle $h E_{g a p}{ }^{+}$so the photocatalytic process can be physically possible, thus ensuring a high efficiency in generating electron-hole pairs (Serpone, 1997; Brucato and Rizzuti, 1997). The semiconductor has a bandwidth $E_{\text {gap }}{ }^{+}=3.2 \mathrm{eV}$ $\left(5.126710^{-19} \mathrm{~J}\right)$ and the energy value at $365 \mathrm{~nm}$ is $5.4423210^{-19} \mathrm{~J}$, therefore $h_{365 n m} E_{\text {gap }}{ }^{+}$. This indicates that the semiconductor activation is promoted at $365 \mathrm{~nm}$, and its low energy due to the closeness of $h_{365 n m}$ and $E_{g a p}{ }^{+}$. Because of the proximity of these two energies, fluctuations in the luminous flux can be despised, Zhang and Anderson (2010), being only the geometry and initial concentration of DCA the explicit purpose.

\subsection{Geometry effect}

The results reveal the "non-intrinsic" nature of the quantum yield relative to the geometric configuration of the system and the initial concentration of DCA.

For the system at initial constant concentration, the quantum yield values for the $\mathrm{CPC}$ reactor are higher than the tubular and axial ones. Furthermore, for the same geometric configuration, the quantum yield is greater at high concentrations.

The first result is related to the total amount of absorbed energy by the system OVRPA to induce the generating process of electron-hole pairs. The Figure 1 shows the quantum yield tendencies depending on the overall net distributed energy by assessing each geometry at initial constant concentration of DCA, The experimental data are shown with symbols. The lines only show the trend of the results when changing from one reactor to another. The results are consistent with 


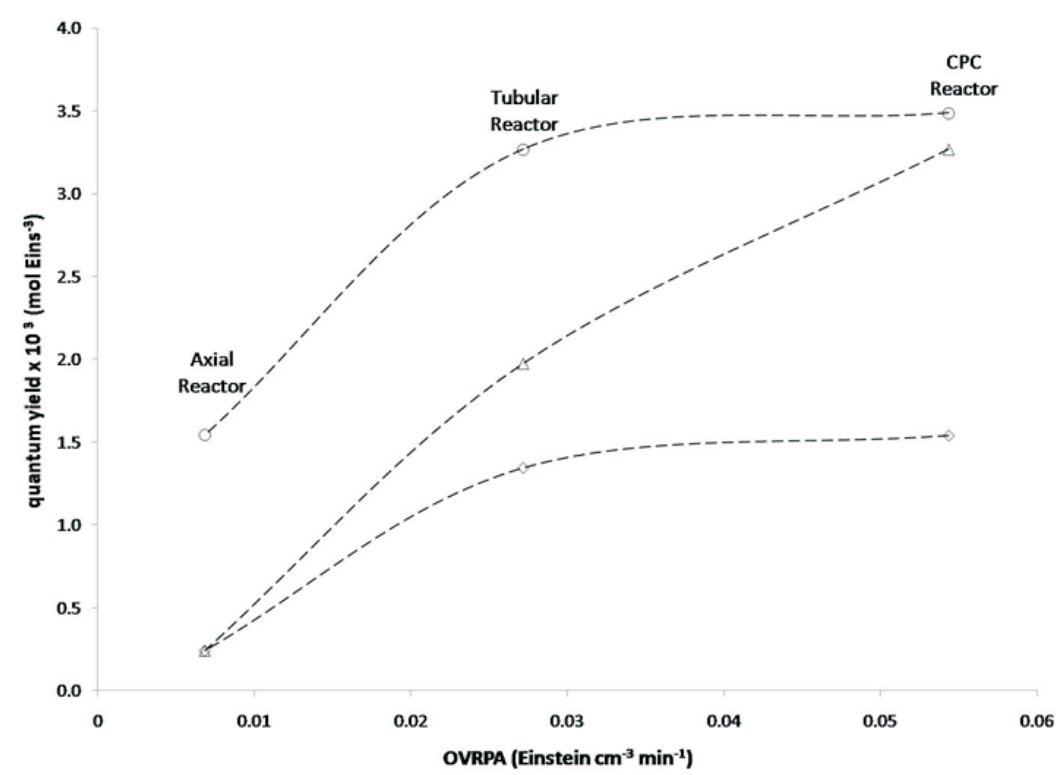

Figure 1. Quantum yields depending on the OVRPA. $\circ C_{D C A, 0}=120 \mathrm{ppm} ; \Delta C_{D C A, 0}=60 \mathrm{ppm} ; \diamond C_{D C A, 0}=30 \mathrm{ppm}$.

those reported in the literature for different systems (Minero and Vione, 2006; Liu and Zhao, 2010).

The Figure 1 shows that for low OVRPA (axial reactor case) the quantum yield declines, and on the other hand, at high absorbed energy (CPC) the quantum yield is high. This is attributable to the diffuse component and to the radiation energy distribution as a result of the CPC collectors (Colina-Marquez et al., 2010).

It further notes that for the same high initial concentration (120 and $60 \mathrm{ppm}$ ), the quantum yield tends to rise with the increase of absorbed energy. However, for lower concentrations, the quantum yield presents an asymptotic tendency towards $0.0015\left(\mathrm{~mol} \cdot\right.$ Einstein $\left.^{-1}\right)$, with a steep change of slope. This may represent a rapid decline (for this concentration) of the generation of electron-hole pairs, in addition to the increase of the recombination rate of the induced pairs (Candal et al., 2001). These results agree with those reported in the literature, (Trujillo et al. 2010, Sagawe et al. 2010, Ballari et al, 2010).

The above observations are related to the bandgap of titanium dioxide. For the three evaluated geometric configurations, the incident luminous flux is the same; and therefore, its photochemical power. The low energy of the radiant field implies that the excitation of the semiconductor is also low due to its value close to the band gap energy and hence the numerical value of quantum yields (Serpone, 1997; Emilene et al., 2008; Trujillo et al., 2010).

However, the geometry effect plays a fundamental role on the system, because it affects the radiant energy distribution within the absorber and how it arrives at each dispersed particle, thus affecting the induction of reactive pairs and kinetics reaction. The results are in agreement with literature, Carp et al. (2004) shows a compelte review about the photoinduced reactivity of titanium dioxide. It is clear that reaction regimes depend on the flux of energy and this affects the electronhole pairs generation and reaction rate.

At high OVRPA, high superficial excitement is generated, more electron hole pairs attack on the reactive species, and hence greater efficiency of redox reactions. This is reflected in higher quantum yields. In contrast, low OVRPA induces less redox reactions, minor transformation of molecules and therefore, lower quantum yields (Serpone et al., 1996; Serpone, 1997; Serpone and Salinaro, 1999; Salinaro et al., 1999; ArancibiaBulnes et al., 2009; Li Puma et al., 2010). 
It can be concluded that the luminous flux and geometry of the reactor play a fundamental role in carrying out photodegradation. A suitable geometric configuration for the provision of the radiation field space implies greater absorbed energy (Blanco et al., 2001) and therefore, greater photodegradation efficiencies reflected in the overall quantum yields and high reaction rates for constant light flows, (Brucato and Rizzuti, 1997a, 1997b; Brucato et al., 2007; Davydov et al., 1999; Moreira et al., 2010).

\subsection{Effect of initial concentration of DCA}

The quantum yield results indicate that for any geometry, this photo-kinetic parameter is higher when working at higher initial concentration of DCA, showing high reaction rates. The quantum yield is lower, and the reaction rate decreases for low initial concentration of DCA. This behavior is consistent with others substances as the phenol, 4-chlorophenol, methanol, and organic compounds (Thomas Jr. et al., 1995; Wang et al., 2002; Sagawe et al., 2003; Cernigoj et al., 2009), In addition, the numerical magnitudes are turning away from each other, as the initial concentration increases (see Figure 1).

The low quantum yields (at low concentration) are attributed to the recombination rate due to electron deficit, presenting a reduction in the transformation of molecules with the same amount of absorbed energy (Monllor-Satoca et al., 2007).

In general, the radiant field of the system provides a constant induction of reactive pairs and an electric potential field inducing constant charges that promote the migration of the holes towards semiconductor-solution interface and of the electrons into the bulk of the semiconductor, restricting the process to an exclusive function of the solution concentration (Monllor-Satoca et al., 2007).

A higher concentration of dissolved DCA ions at the beginning of the process $(5 \geq \mathrm{pH} \geq 3.2)$, provides greater absorption on the surface (Zalazar et al., 2005) and therefore, the neutralization of surface potential, inducing migration of reducer electrons towards it. This will increase the effect of transformed molecules by indiscriminate oxidizing agents. This behavior is attributed to the reactions between different species such as highly oxidizing holes and radicals. This increases the efficiency in the processing of molecules, and comprehensively decreasing the probability of the recombination of electron-hole pairs (Marugan et al., 2006; Monllor-Satoca et al., 2007; Li et al., 2010; Serrano et al., 2009).

By contrast, lower concentrations of DCA will show higher recombination rates, and although the free holes tend to attack the molecules with the same effectiveness, the number of present molecules in the surface reaction will be smaller (Candal et al., 2001), showing a lower net molecule transformation for the same absorbed OVRPA.

\subsection{Prediction of experimental data of DCA photodegradation}

The implementation of the scheme solution presented in section 2.4 allowed predicting DCA photodegradation rates. The Figure 2 shows an example of the prediction of DCA photodegradation, in particulary for $\mathrm{CPC}$ reactor (data not shown for tubular and axial reactors), using the estimated values of non-intrinsec overall quantum yield and the approach of effective radiation model versus the experimental data for all reactors. It was found that the three reactors had a similar behavior. The results show a clear effectiveness of the used numeric scheme solution, plus a satisfactory stoichiometric representation of the DCA photodegradation reaction.

The overall average relative errors associated to the prediction of the experimental data in each reactor are less than $2.5 \%$ (see Table 2). There are minimal discrepancies of the model regarding to the experimental data, as well as predictive effectiveness, the validity of the model approach in this study, and the stability of the proposed numerical algorithm. Similar results were reported using parameter estimating and modeling of reactors (Marugan et al., 2008, 2009; Alfano \& Cassano, 2009). 


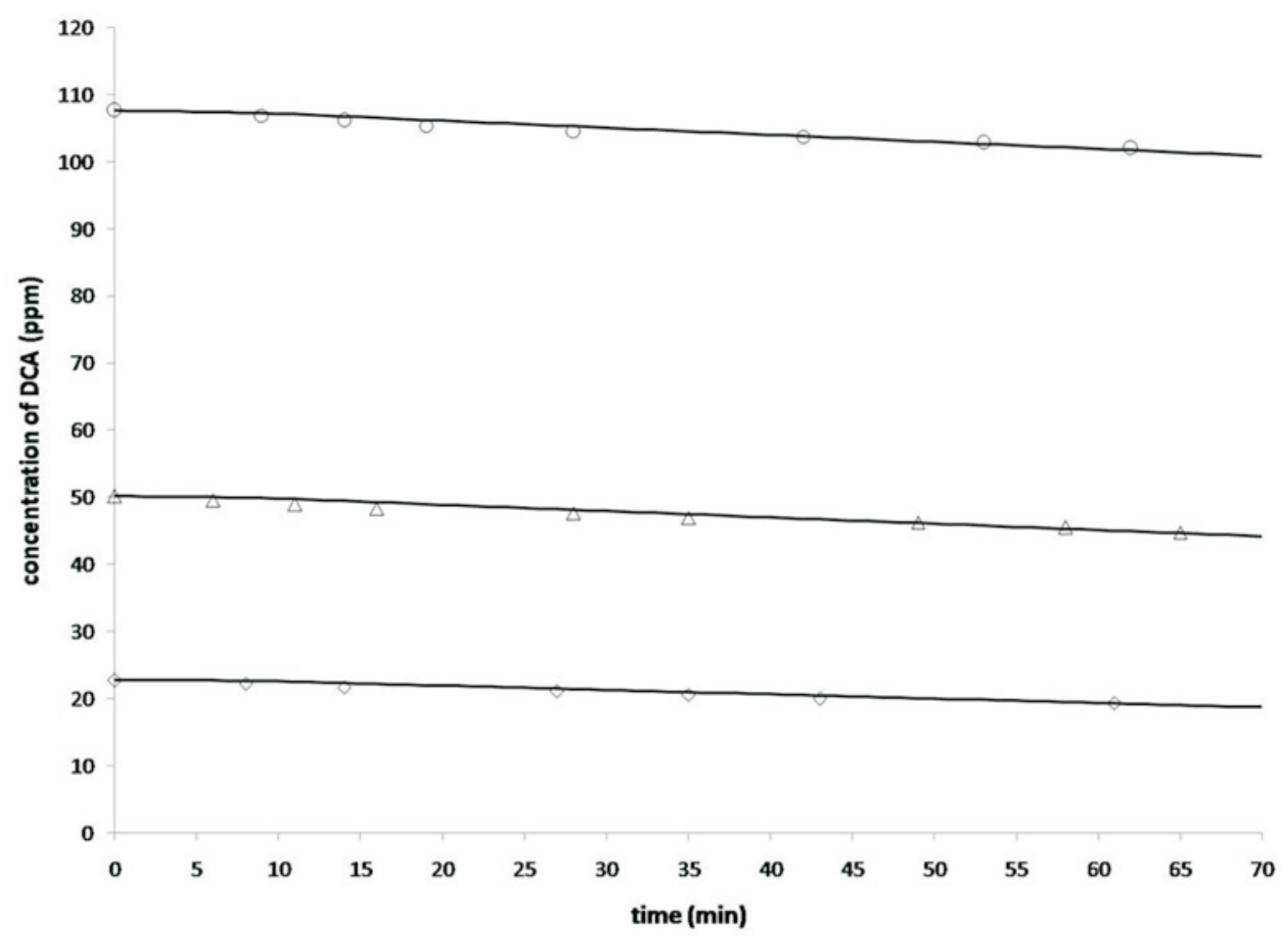

Figure 2. Experimental data simulation for the DCA photodegradation as a function of time for the CPC reactor. $\circ C_{D C A, 0}=120 \mathrm{ppm} ; \Delta C_{D C A, 0}=60 \mathrm{ppm} ; \diamond C_{D C A, 0}=30 \mathrm{ppm}$., Model (一).

Table 2. Overall errors and maximums local errors for the established model.

\begin{tabular}{lcc}
\hline Reactors & \% Overall Average Error & \% Maximum Local Error \\
\hline CPC & 0.53 & 1.27 \\
Tubular & 1.33 & 3.79 \\
Axial & 2.36 & 4.62 \\
\hline
\end{tabular}




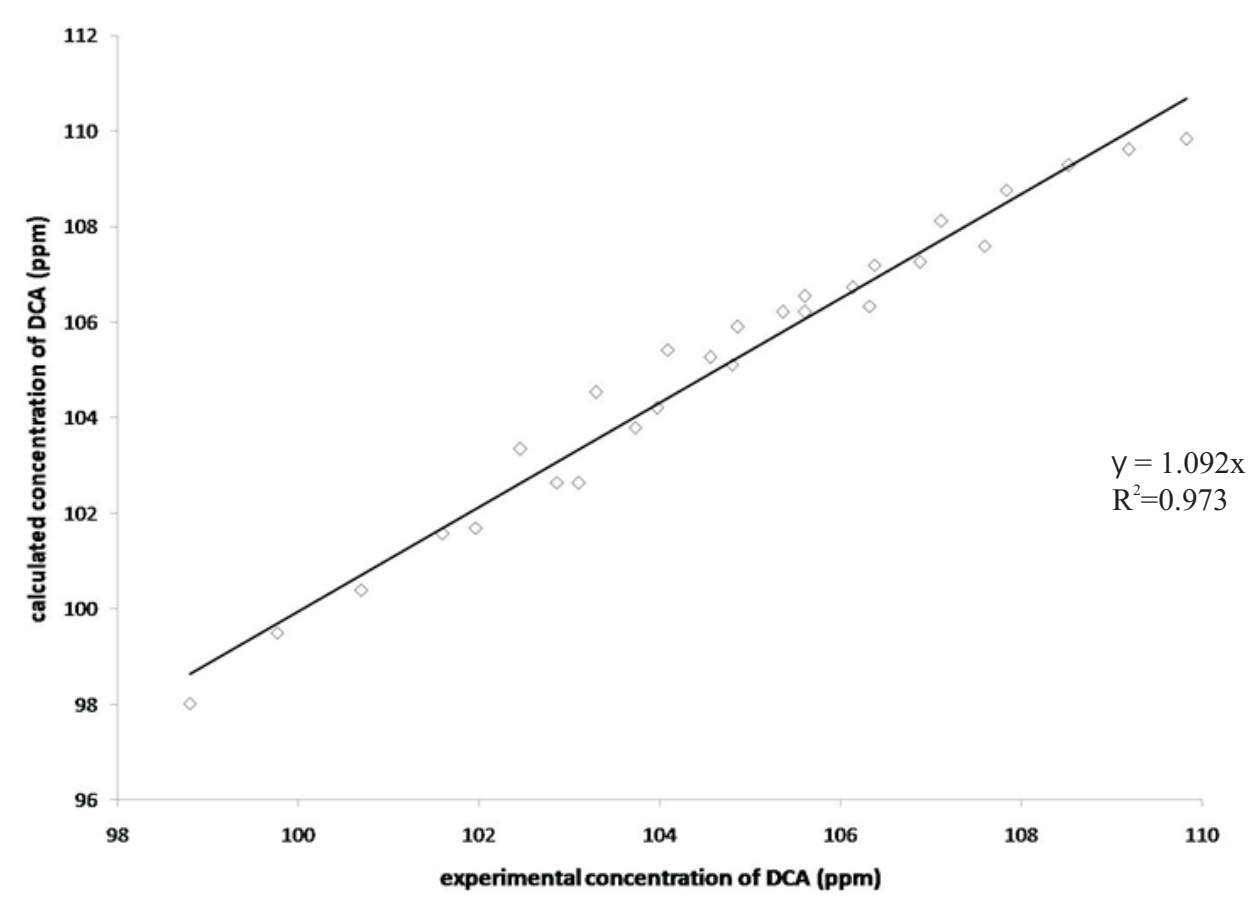

Figure 3. Experimental (all reactors) and simulated data comparison for initial DCA concentration of $120 \mathrm{ppm}$.

The Figure 3 shows a typical behaviour of the difference between the model discrepancy and the all experimental data. The total experimental data were compared to the model prediction for each constant initial concentration of DCA. The correlation coefficients for the three linear functions were $0.973,0.986$ and 0.980 , for initial concentrations of 120,60 and $30 \mathrm{ppm}$, respectively. This ratified the predictive ability of model used.

\section{Conclusions}

The evaluation of the overall quantum yields, coupled to an approach model of effective radiation field, demonstrated the strong influence of the geometry of the system reaction on the photo-kinetic parameters when working at a constant initial concentration of substrate. This suggests that the quantum yields calculated with the model has "non-intrinsic" nature, dependent on the absorbed radiant energy by the system and the initial concentration of the substrate.

\section{Acknowledgements}

The author thank the "Modeling and simulation of intrinsic kinetics of heterogeneous photocatalytic reactions" project, internal code 2520 of Universidad del Valle for the financial support. Also to the National Doctoral Program Support of COLCIENCIAS.

\section{Nomenclature}

$C \quad$ Concentration, $\left[\right.$ mole $\left.\cdot \mathrm{cm}^{-3}\right]$ or $\left[\mathrm{g} \cdot \mathrm{cm}^{-3}\right]$

$E^{a} \quad$ Global volumetric rate of photon absorption, $\left[\right.$ einstein $\cdot \mathrm{cm}^{-3} \cdot \mathrm{min}^{-1}$ ]

$e-\quad$ Semiconductor conduction band electron

$H \quad$ Plank constant, [J·s]

$h^{+} \quad$ Semiconductor valence band hole

$I \quad$ Incident energy, [einstein $\cdot \mathrm{cm}^{-2}$ ]

$K \quad$ Fitting parameter of kinetic model, $\left[\mathrm{mol} \cdot \mathrm{g}^{2} \cdot \min \cdot \mathrm{cm}^{-9}\right.$ ]

$R \quad$ Reaction rate, $\left[\mathrm{mol} \cdot \mathrm{cm}^{-3} \cdot \mathrm{min}^{-1}\right]$

$S \quad$ Superficial area, $\left[\mathrm{cm}^{2}\right]$

$S \quad$ Cartesian coordinate, [cm] 
$T \quad$ Time, $[\mathrm{min}]$

$V \quad$ Volume, $\left[\mathrm{cm}^{3}\right]$

Greek letters

$\beta \quad$ Kinetic photo -kinetic parameter, [mole $\cdot \mathrm{cm}^{-3}$ ]

$Z \quad$ Relative to radiation field

$\Xi \quad$ Geometry parameter

$Y \quad$ Frequency, $\left[\mathrm{s}^{-1}\right]$

$\chi \quad$ Effective longitude, [dimensionless]

$\Lambda$ Wavelength, [nm]

$P \quad$ Phase function

$\eta_{L} \quad$ Geometry parameter or lamp numbers, [dimensionless]

$\kappa_{v} \quad$ Volumetric absorption of semiconductor coefficient $\left[\mathrm{cm}^{-1}\right]$

$\sigma_{v} \quad$ Volumetric scattering coefficient $\left[\mathrm{cm}^{-1}\right]$

$Y$ Transmittance coefficient, [dimensionless]

$T$ Discrepancy function

$\Psi \quad$ Fraction of incident radiation, [dimensionless]

$\Phi \quad$ Quantum yield, $\left[\mathrm{mol} \cdot\right.$ einstein $\left.{ }^{-1} \cdot \mathrm{cm}^{-3}\right]$

\section{Subscripts}

$\begin{array}{ll}\text { A } & \text { Absorption } \\ C a t & \text { Catalyst } \\ D C A & \text { DCA } \\ F & \text { Field } \\ G & \text { Global } \\ \text { Gap } & \text { Band gap } \\ H & \text { High } \\ L & \text { Longitude or low } \\ M & \text { Step in summitry } \\ N & \text { Net } \\ \mathrm{O}_{2} & \text { Oxygen } \\ O & \text { Initial condition } \\ \mathrm{Obs} & \text { Observed } \\ R & \text { Reactor } \\ T & \text { Total }\end{array}$

\section{References}

Alfano, O. M., \& Cassano, A.E. (2009). ScalingUp of Photoreactors: Applications to Advanced Oxidation Processes. Advances in Chemical Engineering 36, 229-287.

Alfano, O., Negro, A., Cabrera, M., \& Cassano, A. (1995). Scattering Effects Produced by Inert Particles in Photochemical Reactors. I. Model and Experimental Verification. Industrial Engineering Chemistry Research 34, 488 - 499.

Arancibia-Bulnes, C. A. \& Cuevas, S. A. (2004). Modeling of the radiation field in a parabolic trough solar photocatalytic reactor. Solar Energy 76(5), 615-622.

Arancibia-Bulnes, C. A., Jiménez, A. E., \& Estrada, C. A. (2009). Development and Modeling of Solar Photocatalytic Reactors. Advances in Chemical Engineering 36, 185-227.

Bahnemann, D., Kholuiskaya, S., Dillert, R., Kulak, A., \& Kokorin, A. (2002). Photodestruction of Dichloroacetic Acid Catalyzed by Nano-Zised $\mathrm{TiO}_{2}$ Particles. Applied Catalysis B: Env. 36, 161 - 169.

Ballari, M., Alfano, O. M., \& Cassano, A. E. (2010). Mass transfer limitations in slurry photocatalytic reactors: Experimental validation. Chemical Engineering Science 65, (17), 4931-4942.

Bandala, E., Arancibia-Bulnes, C., Orozco, S., \& Estrada, C. (2004). Solar Photoreactors Comparison Based on Oxalic Acid Photocatalytic Degradation. Solar Energy, 77, 503 - 512.

Blanco, J., Malato, S., Estrada, C., Peral, J., Sánches, B., \& Cardona, I. (2001). Purificación de aguas por fotocatálisis heterogénea: Estado del Arte. In: Miguel A. Blesa (editores), Eliminación de Contaminantes por Fotocatálisis Heterogénea. CYTED, (Chapter 3). 
Blanco, J., Malato, S., Estrada, C., Bandala, E., Gelover, S., \& Leal, T. (2001). Diseño de Reactores para Fotocatálisis: Evaluación Comparativa de las Distintas Opciones. In: Miguel A. Blesa (editores), Eliminación de Contaminantes por Fotocatálisis Heterogénea. CYTED, (Chapter 11).

Brandi, R., Citroni, M., Alfano, O., \& Cassano, A. (2003). Abslolute Quantum Yields in Photocatalytic Slurry Reactor. Chemical Engineering Science 58, 979-985.

Braham, R.J., \& Harris, A.T. (2009). Review of major design and scale-up considerations for solar photocatalytic reactors. Industrial and Engineering Chemistry Research 48 (19), 8890-8905.

Broyden, C. (1965). A Class of Methods for Solving Nonlinear Simultaneous Equations, Mathematics of Computation 19(52), 577 - 593.

Brucato, A., Grisafi, F., Rizzuti, L., Sclafani, A., and Vella, G. (2007). Quasi-isoactinic Reactor for Photocatalytic Kinetics Studies. Industrial and Engineering Chemistry Research 46 (23), 7684 7690 .

Brucato, A., \& Rizzuti, L. (1997a). Simplified Modeling of Radiant Fields in Heterogeneous Photoreactors. 1. Case of Zero Reflectance. Industrial and Engineering Chemistry Research $36(11), 4740$ - 4747.

Brucato, A., \& Rizzuti, L. (1997b). Simplified Modeling of Radiant Fields in Heterogeneous Photoreactors. 2. Limiting "Two-Flux" Model for the Case of Reflectance Greater Than Zero. Industrial and Engineering Chemistry Research $36(11), 4748$ - 4755.

Cabrera, M., Alfano, O., \& Cassano, A. (1996). Absorption and Scattering Coeficients of Titanium Dioxide Particulate Suspensions in Water. Journal of. Physical Chemistry 100, 20043 - 20050.

Candal, R., Bilmes, S., \& Blesa, M. (2001). Semiconductores con Actividad Catalítica. In: Miguel A. Blesa (editores), Eliminación de Contaminantes por Fotocatálisis Heterogénea. CYTED, (Chapter 4).
Carp, O., Huisman, C.L., \& Reller, A. (2004). Photoinduced reactivity of titanium dioxide. Progress in Solid State Chemistry 32, 33 - 177.

Cassano, A., Martín, C., Brandi, R.; \& Alfano, O. (1995). Photoreactor Analysis and Design: Fundamentals and Applications. Industrial and Engineering Chemistry Research 34, 2155-2201.

Černigoj, U., Štangar, U. L., Trebše, P., \& Sarakha, M. (2009). Determination of catalytic properties of $\mathrm{TiO}_{2}$ coatings using aqueous solution of coumarin: Standardization efforts. Journal of Photochemistry and Photobiology A: Chemistry $201(2-3), 142-150$.

Colina-Marquez, J., Machuca-Martinez, F., \& Li Puma, G. (2010). Radiation Absorption and Optimization of Solar Photocatalytic Reactors for Environmental Applications. Environmental Science \& Technology 44 (13), 5112-5120.

Draper, W. M. (1987). Measurement of Quantum Yields in Polychromatic Light: Dinitroaniline Herbicides. Photochemistry of Environmental Aquatic Systems. In ACS Symposium Series, 327. 268-280.

Davydov, L., Smirniotis, P. G., \& Pratsinis, S.E. (1999). Novel Differential Reactor for the Measurement of Overall Quantum Yields. Industrial and Engineering Chemistry Research $38(4), 1376-1383$.

Dijkstra, M., Koerts E., Beenackers, A., \& Wesselingh, J. (2003). Performance of Inmobilized Photocatalytic Reactors in Continuous Mode. AIChE Journal 49 (3), 734- 744.

Duderstadt, J., \& Martin, R. (1979). Transport Theory. New York: Wiley Inc.

Egerton, T.A., \& Mattinson, J.A. (2010). Effects of particle dispersion on photocatalysis probed by the effect of platinum on dichloroacetic acid oxidation by P25 and nanoparticulate rutile. Applied Catalysis B: Environmental DOI: 10.1016/j.apcatb.2010.05.008. Article in Press. 
Emeline, A.V., Kuzmin, G.N., \& Serpone, N. (2008). Wavelength-dependent photostimulated adsorption of molecular $\mathrm{O}_{2}$ and $\mathrm{H}_{2}$ on second generation titania photocatalysts: The case of the visible-light-active $\mathrm{N}$-doped $\mathrm{TiO}_{2}$ system. Chemical Physics Letters 454 (4-6), 279-283.

Giorges, A. T. G., Pierson, J.A. \& Forney, L.J. (2008). Effect of Reactor Length on the Disinfection of Fluids in Taylor-Couette Photoreactor. Industrial \& Engineering Chemistry Research 47(19), 7490-7495

Goldstein, S. \& Rabani, J. (2008). Polychromatic UV photon irradiance measurements using chemical actinometers based on NO3- and $\mathrm{H} 2 \mathrm{O} 2$ excitation: Applications for industrial photoreactors. Environmental Science \& Technology 42 (9), 3248-3253.

Herrmann, J.-M. (2010). Photocatalysis fundamentals revisited to avoid several misconceptions. Applied Catalysis B: $E n v i r o n m e n t a l$ D O I : 10 . 1016/j.apcatb.2010.05.012. Article in Press.

Imoberdorf, G. E., Taghipour, F., \& Mohseni, M. (2008). Radiation field modeling of multi-lamp, homogeneous photoreactors. Journal of Photochemistry and Photobiology A: Chemistry 198 (2-3), 169-178.

Imoberdorf, G. E., Taghipour, F., Keshmiri, M., \& Mohseni, M. (2008). Predictive radiation field modeling for fluidized bed photocatalytic reactors. Chemical Engineering Science 63 (16), 4228-4238.

Kuhn, H., Braslavsky, S., \& Schmidt, R. (2004). Chemical Actinometry. Pure Applied Chemical, 76(12), 2105-2146.

Li, J., Mailhot, G., Wu, F., \& Deng, N. (2010). Photochemical efficiency of Fe(III)-EDDS complex: \{radical dot\} $\mathrm{OH}$ radical production and $17 \beta$-estradiol degradation. Journal of Photochemistry and Photobiology A: Chemistry $212(1), 1-7$.
Li Puma, G., Puddu, V., Tsang, H.K., Gora, A., \& Toepfer, B. (2010). Photocatalytic oxidation of multicomponent mixtures of estrogens (estrone (E1), 17 $\beta$-estradiol (E2), 17 $\alpha$-ethynylestradiol (EE2) and estriol (E3)) under UVA and UVC radiation: Photon absorption, quantum yields and rate constants independent of photon absorption. Applied Catalysis B:Environmental DOI: 10.1016/j.apcatb.2010.05.015. Article in Press.

Liu, B., \&, Zhao, X. (2010). A kinetic model for evaluating the dependence of the quantum yield of nano- $\mathrm{TiO}_{2}$ based photocatalysis on light intensity, grain size, carrier lifetime, and minority carrier diffusion coefficient: Indirect interfacial charge transfer. Electrochimica Acta 55 (12), 4062-4070.

Machuca, F., Colina-Márquez, J., \& Mueses, M. A. (2008). Determination of Quantum Yield in a Heterogeneous Photocatalytic System Using a Fitting-Parameters Model. Journal of Advanced Oxiditation Technologies 11 (1), 42-48.

Martín, C.A., Baltanás, M.A. \& Cassano, A.E. (1996). Photocatalytic reactors II. Quantum efficiencies allowing for scattering effects. An experimental approximation. Journal of Photochemistry and Photobiology A: Chemistry 94 (2-3), 173-189.

Marugán, J., Hufschmidt, D., López-Muñoz, M., Selzer, V., \& Bahnemann, D. (2006). Photonic efficiency for methanol photooxidation and hydroxyl radical generation on silica-supported $\mathrm{TiO}_{2}$ photocatalysts. Applied Catalysis B: Environmental 62 (3-4), 201-207.

Marugán, J., van Grieken, R., Cassano, A. E., \& Alfano, O. M. (2008). Intrinsic kinetic modeling with explicit radiation absorption effects of the photocatalytic oxidation of cyanide with $\mathrm{TiO}_{2}$ and silica-supported $\mathrm{TiO}_{2}$ suspensions. Applied Catalysis B: Environmental 85 (1-2), 48-60.

Marugán, J., van Grieken, R., Cassano, A. E., \& Alfano, O. M. (2009). Scaling-up of slurry reactors for the photocatalytic oxidation of cyanide with $\mathrm{TiO}_{2}$ and silica-supported $\mathrm{TiO}_{2}$ suspensions. Catalysis Today 144 (1-2), 87-93. 
Moreira, J., Serrano, B., Ortiz, A., \& de Lasa, H. (2010). Evaluation of Photon Absorption in an Aqueous TiO2 Slurry Reactor Using Monte Carlo Simulations and Macroscopic Balance. Industrial \& Engineering Chemistry Research DOI: 10.1021/ie100374f. Article in press.

Minero, C., \& Vione, D. (2006). A quantitative evalution of the photocatalytic performance of $\mathrm{TiO}_{2}$ slurries. Applied Catalysis B: Environmental, 6(3-4), 257-269.

Monllor-Satoca, D., Gómez, R., GonzálezHidalgo, M., \& Salvador, P. (2007). The DirectIndirect model: An Alternative Kinetic Approach in the Heterogeneous Photocatalysis Based on the Degree on Interaction of Dissolved Pollutant Species with the Semiconductor Surface. Catalysis Today 129, 247-255.

Mueses, M. (2008). Un Modelo de Rendimiento Cuántico y Campo de Radiación Efectiva para la Determinación de Cinética de Reacciones Fotocatalíticas Heterogéneas. Tesis de Maestría en Ingeniería, Escuela de Ingeniería Química, Universidad del Valle, Cali, Colombia.

Mueses, M.A., Colina-Márquez, J., \& MachucaMartínez, F. (2008). Degradación Fotocatalítica de Ácido Dicloroacético Aplicando Un Campo De Radiación De Baja Energía, Ingeniería \& Desarrollo. Universidad del Norte. 24, 33-47

Mueses, M.A. \& Machuca, F. (2010a) Una Solución de la Ecuación de Rachford-Rice para Sistemas Multifases Aplicando el Método NewtonRaphson, un Parámetro de Broyden y el Flash Negativo. Información Tecnológica 21 (4), 3-10.

Mueses, M.A. \& Machuca-Martinez, F. (2010b). A New Model for Estimating the Radiation Field in Photocatalytic Heterogeneous Reactors. In: Proceedings of the XXII Congreso Iberoamericano de Catalisis. Con-Cón/Viña del Mar Chile, IP8. 1-5.

Rachel, A., Sarakha, M., Subrahmanyam, M., \& Boule, P. (2002). Comparison of Several Titanium Dioxides for the Photocatalytic Degradation of Benzenesulfonic Acids. Applied Catalysis B: Environmental 37 (4), 293-300.
Rothenberger, G., Moser, J., Grätzel, M., Serpone, N., \& Sharma, D.( 1985). Charge Carrier Trapping and Recombination Dynamics in Small Semiconductor Particles. Journal of American. Chemistry Society 17 (26), 80548059.

Thomas Jr., V.R., Schreiner, A. F., Xie, T., Chen, C., \& Gratzl., J.S. (1995). Photolytic dechlorination of 4-chlorophenol in $\mathrm{O}_{2}$-saturated aqueous solutions in the absence of photocatalysts or additives using $\mathrm{ArF}^{*}(193 \mathrm{~nm})$ and $\mathrm{KrF}^{*}$ (248 $\mathrm{nm})$ excimer lasers. Journal of Photochemistry and Photobiology A: Chemistry 90 (2-3), 183-191.

Salaices, M., Serrano, B., \& de Lasa, H. I. (2001). Photocatalytic Conversion of Organic Pollutants Extinction Coefficients and Quantum Efficiencies. Industrial and Engineering Chemistry Research 40 (23), 5455-5464.

Salinaro, A., Emeline, A.V., Zhao, J., Hidaka, H., Ryabchuk, V.K. \& Serpone, N. (1999). Terminology, relative photonic efficiencies and quantum yields in heterogeneous photocatalysis. Part II. Experimental determination of quantum yields, Pure Applied. Chemistry 71, 321-331

Sagawe, G., Brandi, R. J., Bahnemann, D., \& Cassano. A. E. (2003). Photocatalytic reactors for treating water pollution with solar illumination. I: A simplified analysis for batch reactors. Chemical Engineering Science 58 (12), 2587-2599.

Sagawe, G., Satuf, M. L., Brandi, R. J., Muschner, J. P., Federer, C., Alfano, O. M., Bahnemann, D., \& Cassano, A.E. (2010). Analysis of Photocatalytic Reactors Employing the Photonic Efficiency and the Removal Efficiency Parameters: Degradation of Radiation Absorbing and Nonabsorbing Pollutants. Industrial and Engineering Chemistry Research DOI: 10.1021/ie901753k. Article in press

Serrano, B., Ortíz, A., Moreira, J., \& De Lasa, H.I. (2009). Energy efficiency in photocatalytic reactors for the full span of reaction times. Industrial and Engineering Chemistry Research 48 (22), 9864-9876. 
Serpone, N. (1997). Relative photonic efficiencies and quantum yields in heterogeneous photocatalysis. Journal of Photochemistry and Photobiology A: Chemistry 104 (1-3), 1-12.

Serpone, N., Martin, J., Horikoshi, S., \& Hidaka, H. (2005). Photocatalyzed oxidation and mineralization of $\mathrm{C} 1 \mathrm{C} 5$ linear aliphatic acids in UV-irradiated aqueous titania dispersionskinetics, identification of intermediates and quantum yields. Journal of Photochemistry and Photobiology A: Chemistry 169 (3), 235-251.

Serpone, N., \& Salinaro, A. (1999). Terminology, relative photonic efficiencies and quantum yields in heterogeneous photocatalysis. Part I. Suggested protocol, Pure Applied Chemistry 71, 303-313.

Serpone, N., Sauvé, G., Koch, R., Tahiri, H., Pichat, P., Piccinini, P., Pelizzetti, E., \& Hidaka, H. (1996). Standardization protocol of process efficiencies and activation parameters in heterogeneous photocatalysis: relative photonic efficiencies $\zeta_{\mathrm{r}}$. Journal of Photochemistry and Photobiology A: Chemistry 94 (2-3), 191-203.

Siamak, E., \& Fariborz, T. (2010). Simulation of UV photoreactor for degradation of chemical contaminants: Model development and evaluation. Environmental Science and Technology 44(6), 2056-2063.

Trujillo, F. J., Safinski, T., \& Adesina, A.A. (2010). Oxidative Photomineralization of Dichloroacetic Acid in an Externally-Irradiated Rectangular Bubble Tank Reactor: Computational Fluid Dynamics Modeling and Experimental Verification Studies. Industrial and Engineering Chemistry Research DOI: 10.1021/ie901364z. Article in press.

Wang, C., Rabani, J., Bahnemann, D.W., \& Dohrmann, J.K. (2002). Photonic efficiency and quantum yield of formaldehyde formation from methanol in the presence of various $\mathrm{TiO}_{2}$ photocatalysts. Journal of Photochemistry and Photobiology A: Chemistry 148 (1-3), 169-176.

Wold, A. (1993). Photocatalytic Properties of $\mathrm{TiO}_{2}$ Chemistry Materials 5, 280283.
Zalazar, C. S., Labas, M. D., Martín, C. A., Brandi, R. J., Alfano, O. M., Cassano, A. E. (2005). The extended use of actinometry in the interpretation of photochemical reaction engineering data. Chemical Engineering Journal $109(1-3), 67-81$.

Zalazar, C., Martin, C., \& Cassano, A. (2005). Photocatalytic Intrinsic Reaction Kinetics II: Effects of Oxigen Concentration on the Kinetics of the Photocatalytic Degradation of Dichloroacetic Acid. Chemical Engineering Science 60, 4311-4322.

Zalazar, C., Romero, R., Martin, C., \& Cassano, A. (2005). Photocatalytic Intrinsic Reaction Kinetics I: Mineralization of Dichloroacetic Acid. Chemical Engineering Science 60, 5240-5254.

Zhang, L., \& Anderson, W. A. (2010). A finite model for the prediction of the UV radiation field around a linear lamp. Chemical Engineering Science 65(5), 1513-1521. 